
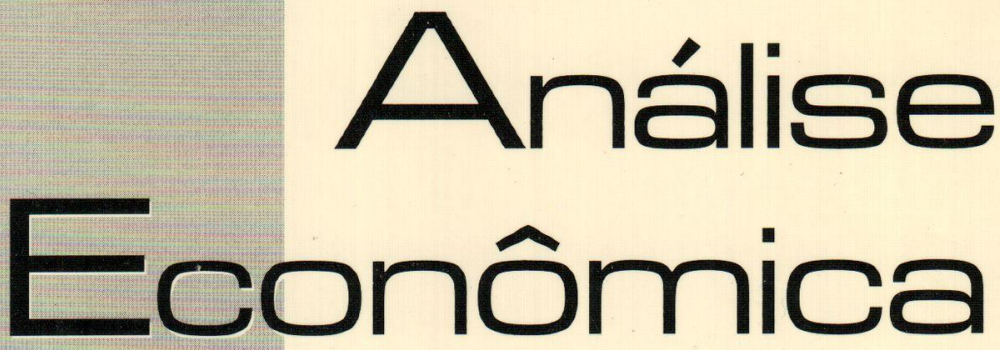

FATOS ESTHLIZADOS E CORRELAÇÁ O NO SETOR BANCÁRIO BRASILEIRO

IGOR AlexandRe C. DE MORAES

Política Monetária, Expectativas e Derivativos: uma ANALISE DO BRASIL PERIODO 1995-98

ROGERIO SOBREIRA

O FEDERAL RESERVE EM DOIS MOMENTOS DISTINTOS: ATUAÇÃO NA GRANDE DEPRESSÃO E NO FINAL DOS ANOS 1990

ROBSON RODRIGUES PEREIRA

BASHLÉIA 2 E ECONOMIAS EMERGENTES: UMA ABORDAGEM MÉDIA-VARIÁNCIA

otaViano Canuto e ANTÓ Nio josé MEIRELLES

VULNERABILIDADES EXTERNAS E INTERNAS DAS ECONOMIAS EMERGENTES E PADRÁ O DE CONTÁ GIO. A EXPERIÉnCIA DA DECADA DE 90

MiLTON PEREIRA OE ASSIS

ENDIVIDAMENTO PÚ BLICO E IMPACTO SOBRE FLUXOS DE CAPITAIS, RISCO-PAIS DIFERENCIAL DE JUROS NO BRASIL (1995-2002): MODELO VAR E TESTES DE CAUSALIDADE FLÁ VIO VILELA VIEIRA

METAS SOCIAIS DE PROCRAMAS DE MICROCRÉ DITO FINANCEIRAMENTE VIÁ VEIS

FERNANDO BATISTA PEREIRA E MARCO CROCCO

Estrutura Produtiva e Performance econó mica das ECONOMIAS ESTAdUAIS BRAsILIRAS NA DECADA DE NOVENTA ADELAR FOCHEZATTO

HISTORIA ECONO MICA Y TEORIA ECONO MICA: ENCUENTROS Y DESENCUENTROS

Gabriel PorciLe

EM BUSCA DA NOÇÃ O EVOLUCIONÁRIA (NEO-

SHUMPETERIANA) DO AUTO-INTERESSE DOS AGENTES: UMA CONTRIBUIÇAO A PARTIR DA LITERATURA SOBRE COOPERAÇÁO INTERFIRMAS

ROBSON ANTONIO GRASS

PRINCiPIOS E APULAÇó Es de REGRESSÁo Local ADALMIR MARQUETTI E LORI VIAL

globalizaçáo, Crescimento e pobreza, a Visäo do BANCO MUNDIAL SOBRE OS EFETTOS DA GLOBALIZAÇÁO NALI DE JESUS DE SOUZA

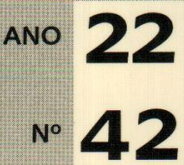




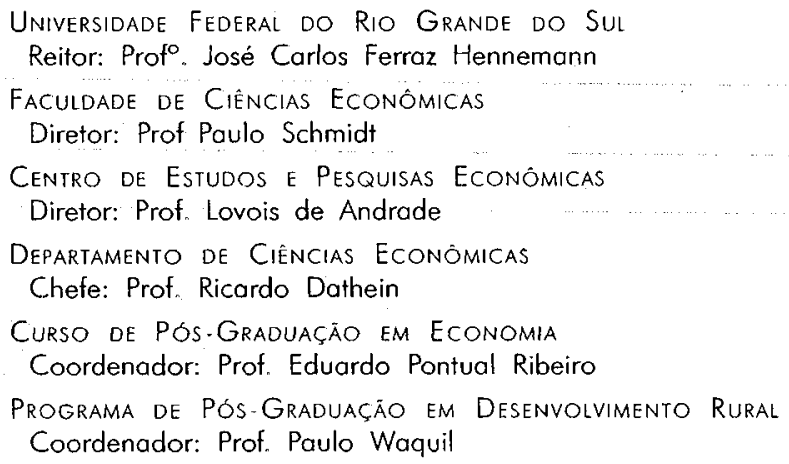

CONSELHO EDITORIAL:

André M. Cunha (UFRGS), Carlos G. A. Mieliz Netto (UFRGS), Carlos H. Hom (UFRGS), Eduardo $A_{n}$ Maldonado Filho (UFRGS), Eduardo P. Ribeiro (UFRGS), Eleutério F. S. Prado (USP), Eugênio Lagemann (UFRGS), Fernando Cardim de Carvalho (UFRJ), Fernando Ferrari Filho (UFRGS), Fernando de Holanda Barbosa (FGV/RJ), Flávio Vasconcellos Comim (UFRGS), Flávio A. Ziegelman (UFRGS), Gentil Corazza (UFRGS), Giácomo Balbinotto Netto (UFRGS), Gilberto de O. Kloeckner(UFRGS), Gustavo Franco (PUC/RJ), Hélio Henkin (UFRGS), Jairo L. Procianoy (UFRGS), Jan A. Kregel (UNCTAD), João Rogério Sanson (UFSC), Joaquim Pinto de Andrade (UnB), Jorge Paulo Araújo (UFRGS), José R. Iglesias (UFRGS), Júlio C. Oliveira (UFRGS), Luis P. Nogueról (UFGS), Luiz E. Faria (UFRGS), Marcelo S. Portugal (UFRGS), Maria Alice Lahorgue (UFRGS), Octávio A. C. Conceição (UFRGS), Orlando Martinelli (UFRGS), Paul Davidson (University of Tennessee), Paulo D. Waquil (UFRGS), Paulo Schmidt (UFRGS), Pedro C. D. Fonseca (UFRGS), Philip Arestis (University of Cambridge), Ricardo Dathein (UFRGS), Roberto C. de Moraes (UFRGS), Ronald Otto Hillbrecht (UFRGS), Sérgio M. M. Monteiro (UFRGS), Sabino da Silvo Porto Jr. (UFRGS), Stefano Florissi (UFRGS) e Werner Baer (University of Illinois at Urbana-Champaign).

COMISSÃO EDITORIAL:

Eduardo Augusto Maldonado Filho, Fernando Ferrari Filho, Gentil Corazza, Marcelo Savino Portugal, Paulo Dabdab Waquil e Roberto Camps Moraes.

EDITOR: Prof. Fernando Ferrari Filho

Egitor Adunto: Prof Gentil Corazza

Secretário: Paulo Roberto Eckent

REVISÁO DE TEXTOS: Vanete Ricacheski

Eottoraçáo Eletrónca: Nucleo de criação e editoraçáo Gráfica UFrgs: leonardo ponso Fundador: Prof. Antônio Carlos Santos Rosa

Os materiais publicados na revista Análise Econômica são da exclusiva responsabilidade dos autores. É permitida a reprodução total ou parcial dos trabalhos, desde que seja citada a fonte. Aceita-se permuta com revistas congêneres. Aceitam-se, também, livros para divulgação, elaboração de resenhas e recensōes Toda correspondência, material para publicação (vide normas na terceira capa), assinaturas e permutas devem ser dirigidos ao seguinte destinatário:

PROF. FERNANDO FERRAR! FILHO

Revista Análise Econômica - Av. João Pessoa, 52 CEP 90040-000 PORTO ALEGRE - RS, BRASIL Telefones: (051) 316-3513 - Fax: (051) 316-3990

Análise Econömíca E-mail: rae@ufrgs.br

Ano 22, $n^{\circ} 42$, morço, 2004 - Porto Alegre

Faculdade de Ciências Econômicas, UFRGS, 2004

Periodicidade semestral, março e setembro.

Tiragem: 500 exemplares

1. Teoria Econômica - Desenvolvimento Regional -

Economia Agrícola - Pesquisa Teórica e Aplicada.

Periódicos. 1. Brasil.

Faculdade de Ciências Econômicas,

Universidade Federal do Rio Grande do Sul. 


\section{O Federal Reserve em dois momentos distintos: ałuação na grande depressão e no final dos anos 1990}

Robson Rodrigues Pereira

Resumo: Existe um consenso de que o Fed falhou no combate à Grande Depressão nos Estados Unidos, por não ter atuado de forma ativa. Nas décadas que sucederam aquele período, a política monetária e as instituiçōes que a exercem evoluíram: atualmente os bancos centrais desempenham papel ativo na condução da política econômica; atitudes passivas diante de situações de crise não seriam assistidas sem questionamentos pelas sociedades modernas. Mas, a despeito das várias transformações ocorridas, as decisões dos policymakers ainda não se tornaram imunes à "exuberância irracional" dos mercados financeiros.

Palavras-chave: Federal Reserve, Grande Depressão, Política Monetária.

Abstract: 'There is consensus about the Fed's failure to have taken more incisive measures during the Great Depression in USA. In the following decades, monetary policy and institutions have evolved in a different way: nowadays central banks have a more active role in the conduction of economic policy, such that the choice of a passive stance during periods of economic crises would not be accepted unquestionably by modern societies. Nevertheless, in spite of the various transformations that took place in the working of central banks, the decisions made by the policymakers have not yet become immune to the so-called "irrational exuberance" of the financial markets.

Keywords: Federal Reserve Bank, Great Depression and Monetary Policy

Classificação JEL: E58, N12.

\section{Introdução}

Dentre as tantas crises ocorridas na história do capitalismo, a mais profunda e extensa foi aquela presenciada entre 1929 e 1933. Tal foi seu impacto em todos os continentes, que o período ficou conhecido como o da Grande Depressão.

E-mail: robsonrp@usp.br. Quero agradecer pelas valiosas observações e sugestões de Dante Mendes Aldrighi, Gilberto Tadeu Lima, Sérgio Naruhiko Sakurai e do parecerista anônimo. Erros remanescentes são de minha inteira responsabilidade. 
Os indicadores para o epicentro dessa crise - os Estados Unidos - são dramáticos. Somente nos seus 18 primeiros meses, a produção industrial norte-americana declinou 37\%. A partir do crash da Bolsa de Valores de Nova York (NYSE), em outubro de 1929 , criou-se uma volatilidade no mercado financeiro que, gerando incertezas acerca do futuro, contribuiu para que o consumo privado fosse contraído. A retração verificada na demanda levou à queda no nível geral de preços - entre julho de 1929 e julho de 1932, a deflação do Índice de Preços ao Produtor foi superior a $40 \%$. Estima-se que, nos quatro anos da crise, $5 \mathrm{mil}$ bancos tenham suspendido atividades e 85 mil empresas tenham falido. O desemprego atingiu a marca de $25 \%$. O produto do país caiu, em média, 8,5\% ao ano entre 1930 e 1933. A produção industrial retornou aos patamares de 1929 somente em 1937, alguns anos após o início da administração do presidente Roosevelt, que decretou a mudança do regime cambial do país e estabeleceu o Novo Pacto (New Deal). ${ }^{1}$

O quadro acima descrito gera ainda hoje um intenso debate sobre o papel da política monetária no combate à crise. Neste artigo será analisada a atitude do Federal Reserve antes e durante a Grande Depressão. Sob uma análise ex post, verifica-se que a Autoridade Monetária dos EUA não agiu para mudar a situação crítica que se desenvolveu no final dos anos 1920, ou o fez de forma limitada. As principais justificativas apresentadas para explicar essa passividade são investigadas neste trabalho.

A forma de fazer política monetária sofreu transformações ao longo das décadas posteriores ao período estudado, assim como os próprios bancos centrais. Contudo, alguns aspectos relevantes para a tomada de decisões em 1928, continuam presentes.

$\mathrm{Na}$ seção seguinte será vista a evolução da Autoridade Monetária nos Estados Unidos, apontando-se os acontecimentos e conflitos que influenciaram as principais decisões dos policymakers na segunda metade da década de 1920. Na seção 3 serão abordadas algumas das principais teorias que explicam a passividade do Banco Central norte-americano diante da crise. $\mathrm{Na}$ seção 4 será analisado o comportamento do Fed em outro

${ }^{1}$ As fontes desses dados encontram-se principalmente em Romer (1993) e Wilner e Costa (2002). Em relação aos bancos, Bernanke (1983) destaca a predominância de pequenas instituições no sistema financeiro do país, na época. Vale destacar, contudo, que existem registros de falências de grandes bancos. 
momento da histórica econômica dos EUA - a segunda metade da década dos anos 1990 - na qual o Banco, com maior grau de maturidade, toma atitudes diferentes daquelas tomadas durante a Grande Depressão. Argumentar-se-á que essa mudança insere-se nos movimentos de evolução da política monetária e dos bancos centrais de um modo geral. Na seção 5 conclui-se que as chances de aquela tragédia se repetir são menores nos dias atuais, mas algumas das questões que influenciavam as decisões dos bancos centrais há algumas décadas permanecem ainda hoje.

\section{A evolução da política monetária ao longo da década de 1920: conflitos e raízes da Grande Depressão}

Atualmente são três os principais instrumentos de política monetária: política de redesconto (empréstimos de liquidez), operações de mercado aberto (open market) e gerenciamento de depósitos compulsórios. A utilizaçāo do primeiro desses instrumentos é o que caracteriza o banco central como emprestador de última instância, mas atualmente são as operações de open market que constituem o mais importante fator de determinação de alterações da base monetária na maioria dos países. Entretanto, essas operações nem sempre constituíram o principal instrumento de ação da Autoridade Monetária. O estudo de caso dos Estados Unidos constitui exemplo interessante.

Ao ser criado, em 1913, o Federal Reserve System (Fed) tinha como objetivo principal evitar instabilidades financeiras através da disponibilidade rápida dos fundos necessários a bancos em dificuldades. $^{2}$ Desse modo, o Federal Reserve Act estabeleceu que os bancos membros do Sistema deveriam manter uma reserva mínima com o Reserve Bank do distrito ao qual pertenciam. Mishkin (2000, p. 235) chama a atenção para essa característica singular do banco central norte-americano: uma estrutura composta, desde sua criação, por doze bancos regionais semi-autônomos, que deveriam cooperar entre si. O jovem Fed iria sofrer transformações e aperfeiçoamentos ao longo dos anos seguintes

\footnotetext{
${ }^{2}$ Desde sua independência, os EUA vivenciaram duas experiências de estabelecimento de banco central. Tais experiências não obtiveram êxito, culminando na dissolução do First Bank of United States em 1811 e na expiração da carta-patente do Second Bank of United States em 1836, não-renovada. Ver Mishkin (2000, p. 235) para mais detalhes.
} 
assim como a própria política monetária determinada e executada por bancos centrais que, na época da criação do Sistema, somavam apenas 20 instituições em todo o mundo. ${ }^{3}$

A intenção dos idealizadores do Fed era de que este tivesse a chamada janela de redesconto como principal ferramenta da política monetária. Seguindo a Real Bills Doctrine (RBD), determinou-se que somente papéis (de curta maturidade) emitidos para propósitos de crédito agrícola, industrial ou comercial seriam elegíveis para o redesconto. Como contrapartida, o banco central forneceria papel-moeda, as Federal Reserve Notes. Ao limitar as operações de redesconto através da elegibilidade dos papéis aceitos, o objetivo era acomodar flutuações na economiă real, evitando inflação ou especulação financeira. A relação de causalidade defendida pela RBD era dos preços $(\mathrm{P})$ e do nível real de atividade (Q) para o estoque de moeda $(\mathrm{M})$ necessário para acomodar aquele nível nominal $(\mathrm{P} \times \mathrm{Q}) .{ }^{4}$ De acordo com a Doctrine, $\mathrm{P}$ e $\mathrm{Q}$ são exógenos, sendo o primeiro ajustado de acordo com o nível do segundo.

Mishkin (2000, p. 291) aponta que, após a recessão de 192021, o volume de operações de redesconto caiu dramaticamente, reduzindo as receitas do Fed. ${ }^{5}$ Por isso, este começou a efetuar compras de títulos remunerados. Com o passar do tempo, alguns membros dos Reserve Banks, especialmente os de Nova York, perceberam que as operações de mercado aberto afetavam as reservas dos bancos, as taxas de juros de mercado e as condições de crédito.

Sob a liderança de Benjamin Strong, o Reserve Bank de Nova York (RBNY) começou a utilizar o open market para implementar uma política monetária mais ativa. As substanciais aquisições de títulos realizadas em 1924 e 1927 constituíram resposta eficiente às recessões de 1923-24 e 1926-27. Entretanto, como destacado por Wheelock (2002), as reais intenções do governador do RBNY ao comandar tais operações constituem objeto

\footnotetext{
${ }^{3}$ A quantidade de bancos centrais no começo da década de 1910 é citada em Pollard (2003, p. 11).

${ }^{4} \mathrm{Na}$ época, a mensuração do produto real (Q) ficou por conta do índice de produção industrial, criado pelo próprio Fed em 1922. O nível de preços $(\mathrm{P})$ era medido pelo Índice de Preços no Atacado. Vide Humphrey (2001) para mais detalhes.

${ }^{5}$ Quando o Fed foi criado sua receita provinha basicamente dos juros que recebia sobre os empréstimos de desconto que fazia aos bancos membros do Sistema.
} 
de divergência entre os estudiosos. Eichengreen (2000, p. 92 e 102), por exemplo, advoga que tais operações foram realizadas com o intuito de pressionar para baixo as taxas de juros locais e, com isso, contribuir para manter o padrão-ouro na Grã-Bretanha, que passava por dificuldades de reservas. As ações de Strong também geraram controvérsia entre os membros do Board do Fed, pois muitos deles, adeptos da RBD, acreditavam que, ao agir por iniciativa própria, o Sistema poderia incentivar atividades financeiras especulativas.

Grandes mudanças ocorreram nos padrões de consumo e gastos do setor privado após a I Guerra Mundial. O desenvolvimento de novos instrumentos de crédito - entre os quais destacase a venda financiada - possibilitou que as massas tivessem acesso aos novos bens duráveis de consumo, tais como automóveis e eletrodomésticos. As conseqüências desses novos padrões não demoraram a surgir: segundo Kubik (1996, p. 831), a dívida do consumidor como proporção da renda pessoal disponível registrou considerável aumento, tendo passado de 4,68\% em 1920 para 9,34\% em 1929.

A liquidez gerada com as operações no mercado aberto favoreceu a febre consumista que tomou conta da sociedade americana da época, bem como o incremento de operações especulativas no mercado acionário. Wilner e Costa (2002, p. 17) relatam um exemplo típico da bolha especulativa que se formou no mercado de ações: "As pessoas começaram a pagar preços desproporcionais por ações, contando com sua valorização permanente. As favoritas eram as novas tecnologias: pela primeira vez, automóveis, rádios e eletrodomésticos estavam sendo produzidos em massa e passagens de aviāo eram vendidas [...] A RCA, símbolo da era do rádio, era então o que a $\mathrm{AOL}$ seria para os 90 . Suas ações subiram de US\$1,50 em 1921 para US\$ 85 no início de 1928 e US $\$ 114$ em 1929, 73 vezes o seu lucro e 17 vezes seu valor contábil".

No encontro de janeiro de 1928, o Open Market Investment Commitee (OMIC) - colegiado sob chefia do governador do RBNY - estabeleceu uma mudança na orientação da política expansionista desenvolvida até então. O Fed passou a implementar uma política contracionista, materializada tanto em aumentos na taxa de redesconto quanto em operações de venda de títulos. Existem divergências no que tange à intensida- 
de dessa política, quando comparada com outros momentos na década de $1920 . .^{6}$ O consenso, contudo, é que as causas imediatas da Grande Depressão encontram raízes nessa mudança de rota na política monetária.

Mas quais teriam sido os motivos que levaram a essa mudança na condução da política monetária? Uma primeira resposta encontra respaldo nas reformas econômicas realizadas com êxito a partir de 1926 na França. Como resultado de tais reformas houve absorção de ouro de outras partes do mundo: as reservas do Banco da França aumentaram 76\% entre dezembro de 1926 e dezembro de 1928 (Hamilton, 1987, p. 147). Preocupados com os efeitos negativos que começaram a pressionar as reservas norteamericanas, os membros do OMIC preferiram agir, adotando uma política contracionista.

A constatação de que outros motivos também poderiam estar por trás da mudança de atitude do Fed surge a partir da manutenção do aperto monetário mesmo após as taxas de juros mais elevadas terem revertido a fuga de capital. Por isso, Eichengreen (2000), Friedman e Schwartz (1963), Hamilton (1987), Romer (1993) e Wheelock (2002) afirmam que o principal propósito para implementar uma política monetária contracionista foi o de conter o boom no mercado acionário.

Wheelock (2002) também destaca que o tema de muitos dos debates internos no Sistema era se o Fed deveria responder ao rápido aumento do preço das ações e dos empréstimos de bancos e brokers para financiar a compra das mesmas. A forma como tal resposta ocorreria também foi objeto de discussões: se por imposição de proibições e restrições ou por aumento de juros e venda de títulos. Entretanto, prevaleceu a teoria de que a melhor política seria a não-intervenção.

A perda de ouro em função da fuga de reservas para a França, bem como as medidas adotadas a partir de janeiro de 1928, reduziu a base monetária no primeiro semestre daquele mesmo ano. Entretanto, como destacado por Hamilton (1987), Friedman e Schwartz (1963) e Romer (1990), parte dessa perda foi compensada por uma maior procura por empréstimos do Fed

- Tais divergências ficam patentes com as opiniōes de Hamilton (1987, p, 147) e Romer (1993, p. 29). 
via redesconto, o que pode ser explicado pelo seguinte argumento: a percepção de aumento do produto marginal do capital - que, segundo Hamilton, se deve às novas oportunidades tecnológicas da época - resultou em maior procura por empréstimos dos bancos comerciais - para financiar o jogo na bolsa aumentando a demanda desses últimos por reservas. ${ }^{7}$

A combinação da política monetária deliberadamente contracionista - mantida ao longo de 1928 e do ano seguinte com o aumento da demanda por recursos monetários implicou a elevação das taxas de juros nominais e reais praticadas pelos bancos. Os efeitos dessa política são apontados para explicar o início da recessão norte-americana. Após atingir o pico, em julho de 1929, a produção industrial do país começou a registrar contração. Não demorou muito para que os preços das ações começassem a refletir a situação econômica vigente. Nas palavras de Galbraith (1988, p. 80), "[...] o mercado acionário é apenas um espelho que, talvez como nesse caso, fornece um pouco tardiamente a imagem da situação econômica subjacente ou fundamental[...] Em 1929, a economia caminhava para a crise, crise essa que, finalmente, desembocou violentamente em Wall Street". Para citar apenas um dos muitos exemplos, Wilner e Costa (2002, p. 18) relatam que os preços das ações da RCA desabaram para US $\$ 26$ em outubro daquele mesmo ano, quando ocorreu o crash da NYSE.

Epstein e Ferguson (1984, p. 963) destacam que parte considerável dos empréstimos realizados pelos bancos comerciais de Nova York foi feita para financiar o boom acionário, justificando uma ação rápida por parte do RBNY. Tal ação ocorreu através de compras de títulos no mercado aberto em quantias superiores àquelas autorizadas anteriormente pelo OMIC, o que gerou discussões internas no Sistema, com predominância das vozes que advogavam pela não-intervenção. Algumas das teorias que justificam essa passividade diante do colapso econômico são abordadas na seção seguinte.

${ }^{7}$ Hamilton (1987, p. 152) relata que entre dezembro de 1927 e julho do ano seguinte a base monetária foi reduzida em US $\$ 889$ milhões (cerca de $12 \%$ ), como resultado da perda de reservas para a França e prática de políticas monetárias que diminuíram a liquidez do mercado. Entretanto, os empréstimos no redesconto registraram aumento de US\$561 milhōes no mesmo período. 


\section{A inércia da Autoridade Monetária durante a Grande Depressão}

No clássico A Monetary History of the United States, 1867 . 1960, Friedman e Schwartz enfatizam que as discussões internas no Fed, bem como sua passividade perante a crise, ocorreram pela falta de um líder no Sistema. Com o falecimento de Strong em outubro de 1928, o RBNY perdeu a liderança e o poder de persuasão que tinha sobre os demais Reserve Banks, descritos pelos autores como paroquiais e preocupados com os problemas regionais imediatos. Esses conflitos caracterizavam o Banco Central norte-americano como uma instituição fraca e descentralizada, bem diferente do poderoso e influente Fed dos dias atuais.

A questão que se segue refere-se aos motivos pelos quais a maioria dos integrantes do Sistema preferiu adotar uma posição passiva diante da crise que se desenvolvia no país. Fiéis ao arcabouço da RBD, muitos dos membros do Board advogavam um papel não-intervencionista e acomodatício para o Banco Central. Permitir a redução do crédito disponibilizado ao público não significaria nada mais do que a mera adequação ao menor nível de produto nominal para o qual a economia fora deslocada.

Havia uma visão de que o ajuste deveria ocorrer porque antes existira superprodução. Representantes de alguns Reserve Banks enxergavam a queda nos preços de commodities como conseqüência de um excesso de produção que se desenvolvera anteriormente e da mudança nos padrões de crédito: "This overproduction did not manifest itself until a year ago because, under the stimulus of instalment buying and an unreasoning belief in long-continued and unprecendented prosperity, overbuying kept pace with overproduction" (KUBIK, 1996, p. 837). ${ }^{8}$ Nas palavras de Eugene Black, governador do Reserve Bank de Atlanta, "The cause of the business depression is due primarily to the failure of the American people to live within their means"

\footnotetext{
${ }^{8}$ Citado na referência indicada a partir de atas de reunião do Open Market Policy Conference (OMPC), realizada em setembro de 1930. De acordo com Friedman e Schwartz (1963), o OMIC foi substituído pelo OMPC em março de 1930. Este ültimo, ao contrário do primeiro, foi constituído pelos governadores dos doze Reserve Banks. Cada um dos bancos regionais poderia utilizar discricionariedade em relação às decisões do comitê. Entretanto, caso não participasse de alguma operação de mercado aberto determinada em reunião, deveria esclarecer as razóes ao Board.
} 
(KUBIK, 1996, p. 835). ${ }^{9}$ Portanto, a ordem do dia era permitir a liquidação dos estoques e do crédito ao consumidor, de modo a, nas palavras de Kubik, expurgar a podridão do Sistema.

Enquanto os debates internos ocorriam, a crise assumia proporções gigantescas. Um conjunto de acontecimentos contribuiu para explicar sua intensificação, principalmente a partir de 1930 . Destacam-se os três relacionados abaixo. Deve-se notar que aspectos não-monetários também estiveram presentes:

1) A alta volatilidade dos preços das ações (verificada principalmente entre novembro de 1929 e meados do ano seguinte) introduziu incertezas sobre a renda futura. Segundo Romer (1990), tal volatilidade foi superior àquela registrada na crise acionária de 1987. Essas incertezas espalharam-se pela economia, atingindo consumidores que, por sua vez, passaram a postergar gastos, especialmente em bens duráveis. A maior parte da queda do produto nacional entre 1930 e 1933 é explicada por decréscimos no consumo privado e nos investimentos fixos (Romer, 1993, p. 30);

2) A deflação resultante da retração na demanda e na produção, ao aumentar a dívida real do setor privado, gerou aumento do serviço da dívida daquele setor, de $9 \%$ da renda nacional de 1929 para 19,8\% em 1932-33 (Bernanke, 1983, p. 260). A conseqüência desse incremento veio sob a forma de aumento nos índices de insolvência e de falência, principalmente entre as pequenas empresas. Além do mais, o aumento das taxas reais de juros, causado pela deflação, também inibiu investimentos;

3) A perda de confiança no sistema financeiro que se seguiu ao colapso da NYSE e ao aumento dos índices de insolvência provocou ondas de corridas contra os bancos, o que gerou falên. cias bancárias. ${ }^{10}$ Os depósitos como proporção da moeda foram reduzidos e, com isso, o multiplicador monetário e a oferta de crédito também diminuíram. Romer (1993, p. 32) enfatiza a passividade do Sistema, afirmando que nada foi feito para ampliar a base monetária. O emprestador de última instância não estava desempenhando seu papel da forma adequada.

A trajetória de passividade teve um instante de desvio no início de 1932. Friedman e Schwartz (1963), assim como Epstein e Ferguson (1984), afirmam que após o crash da Bolsa o RBNY

9 Citado a partir de artigo publicado no The New York Times de 15/10/1930.

to Ver Friedman e Schwartz (1963, p. 342-359) para mais detalhes. 
pressionou o Sistema por uma política monetária ativa, mas suas propostas foram rechaçadas pelos demais distritos. Uma divergência entre as duas duplas de autores encontra-se no grau de preocupação do Fed com o padrão-ouro vigente na época. Para Friedman e Schwartz, o padrão-ouro não exerceu influência na passividade do Banco Central, pois existia um estoque de ouro suficiente para perseguir políticas expansionistas - pelo menos até o abandono do câmbio fixo pela Grã-Bretanha, em setembro de 1931. Já Epstein e Ferguson advogam o contrário, afirmando que existiu oposição interna às operações de compras no mercado aberto por conta de preocupações com o padrão-ouro.

A resposta do Fed à pressão exercida sobre o dólar a partir da desvalorização da libra esterlina materializou-se através da elevação da taxa de redesconto. Tal política reverteu a fuga de capitais, mas provocou novas ondas de queda nos preços e falências (Epstein e Ferguson, 1984, p. 966). A partir de então, pressões advindas de bancos e empresas, assim como do Congresso, desembocaram em um plano para recuperação da economia, no início de 1932." Esse plano incluiu um programa de redução das taxas de descontos e compras de títulos públicos, com o objetivo de reverter a forte tendência deflacionária vigente. ${ }^{12}$ Naquele mesmo ano, a promulgação do Glass-Steagall Act permitiu que bônus do Tesouro também passassem a ser aceitos como respaldo das Federal Reserve Notes em circulação, liberando parte do estoque de ouro para que o Banco Central enfrentasse eventuais corridas contra a moeda. ${ }^{13}$

O programa de operações expansionistas adotado pelo Fed em abril de 1932 foi abandonado em julho do mesmo ano. As razões, segundo Epstein e Ferguson (1984, p. 968-977), vão desde oposições de governadores de vários distritos até perdas financeiras que os bancos comerciais passaram a sofrer com a queda nos juros, constituindo tais prejuízos a tese central do trabalho desses autores. ${ }^{14}$ Depois disso, novamente um Fed passivo.

\footnotetext{
11 A literatura pesquisada, infelizmente, não traz insights acerca de pressōes anteriores advindas da sociedade, do Executivo ou do Legislativo - para que o Fed alterasse sua política perante a crise. Eichengreen (2000, p. 124) sugere que as pressões exercidas pelo Congresso em 1932 relacionam-se à campanha eleitoral.

12 O termo apropriado para expressar a utilização da política monetária com o objetivo de reverter tendências deflacionárias para inflacionárias é reflação.

${ }_{13}$ Ver Eichengreen (2000, p. 102) e Epstein e Ferguson (1984, p. 967) para mais detalhes.

${ }_{14}$ Epstein e Ferguson (1984, p. 975) observam que a queda nos juros resultou em saques de depósitos de estrangeiros, forçando a liquidação de bonds e conseqüente perda nos seus portfólios e margens de ganhos.
} 
Uma questão que merece uma investigação mais profunda relaciona-se à crença na $\mathrm{RBD}$ que, como sugere o exposto até aqui, foi bastante arraigada nas visões de mundo dos policymakers norte-americanos da época. Um ponto a ser discutido é se existia alguma alternativa teórica disponível para a condução da política monetária na época. Humphrey (2001, p. 67) afirma que sim: "The quantity theory framework passed the test with flying color. Its indicators - money stock, price level, and real rates of interest correctly signaled that monetary policy was extraordinarily restrictive and likely to precipitate a contraction". Entretanto, essa abordagem teórica foi deliberadamente rejeitada pelo Fed '(Humphrey, 2001, p. 65).

No início do século XX, a Teoria Quantitativa da Moeda (TQM) ganhou impulso com os trabalhos desenvolvidos por Irving Fisher. Na Teoria, a relação de causa é da moeda para o produto e não o contrário (como é defendido pela RBD). Neste caso, a Autoridade Monetária tem papel ativo para estabilizar a economia e não mais o de simplesmente acomodar variações no produto, atuando de forma pró-cíclica.

Mas a RBD não se apresentou como uma teoria imutável ao longo do tempo. A principal mudança que sofreu veio a partir da descoberta dos efeitos das operações do mercado aberto. Operações com títulos públicos constituem, antes de tudo, uma política ativa e, além disso, tais títulos não são emitidos com propósitos de crédito agrícola, comercial ou industrial. Como explicar operações no open market dentro de um contexto de política monetária acomodatícia? Uma das interpretações advoga que, ao vender e comprar títulos públicos, o Banco Central induz os bancos comerciais a, respectivamente, tomar e liquidar empréstimos realizados no redesconto, de acordo com as necessidades de crédito da economia real. Isso ocorre pelo desequilibrio causado às reservas disponíveis para empréstimos dos bancos aos clientes e a conseqüente necessidade de ajustamento (Humphrey, 2001, p. 85).

Se o Fed tivesse dado maior ênfase aos indicadores propostos pela TQM, teria obtido indícios de que a política monetária estava apertada. Humphrey advoga que, além da queda expressiva do nível de preços, o Sistema deveria ter dado importância à taxa real de juros que, em meados de 1931, registrou um nível de $10,5 \%$, mais de seis pontos percentuais acima do nível registrado em 1929 (Humphrey, 2001, p. 88). Assim sendo, a falha de política 
monetária ocorreu em virtude de o Banco Central norte-americano ter enfatizado indicadores como o nível de empréstimos tomados no redesconto e taxas de mercado que, na fase inicial da Depressão (1929-31), sinalizaram indícios de uma política monetária frouxa. ${ }^{15}$ Nessa mesma linha de argumentação encontram-se Brunner e Meltzer (1968), porém com um trabalho publicado três décadas antes do de Humphrey.

Apesar de não existir unanimidade em relação a todos os pontos que tangenciaram a Grande Depressão, a percepção de que o Federal Reserve falhou em algum momento parece ser uma constante nas análises. Na ocorrência de uma crise no consumo e na produção ou simplesmente de sinais que a antecedam, o Banco Central atual agirá de forma mais ativa em relação à atuação do jovem Fed? A resposta a essa questão exige uma avaliação da evolução sofrida pelos bancos centrais ao longo das décadas posteriores àquela catástrofe econômica. Esse será o próximo passo neste trabalho.

\section{O Fed na segunda metade dos anos 1990: evolução e mudança de atitude}

Conforme visto na seção anterior, os dois principais argumentos abordados neste artigo acerca das causas da passividade do Fed diante da crise são: a) a ausência de um líder como Strong, capaz de comandar uma operação de salvamento da economia somada à existência de uma estrutura descentralizada na tomada de decisões; e b) a desconsideração de que outras teorias disponíveis poderiam explicar melhor o estado da economia. Dada a complexidade envolvida na Grande Depressão, não se pode descartar a possibilidade de que o segundo argumento seja justificado pela existência do primeiro, ou seja, que ambos os fatos atuaram conjuntamente.

Passados mais de 70 anos após o início da Grande Depressão, um aspecto que permeia as decisões da política monetária do Fed está tão presente hoje quanto estava na década de 1920: a exube-

${ }^{15}$ Segundo Humphrey, foram os niveis de empréstimos e as taxas de juros nominais (como as que balizavam as negociaçōes dos títulos de curto prazo do Tesouro) os dois indicadores utilizados pelo Fed para justificar a inércia adotada. 
rância irracional intrínseca aos mercados financeiros. Nos EUA dos anos 1990, uma vez mais as novas tecnologias impulsionaram investimentos que incrementaram o aumento da produtividade. Esse incremento, por sua vez, contribuiu para manter a inflação e os juros em baixa, o que elevou os lucros reais e os preços de ações das empresas. Com o baixo custo do dinheiro, a economia norteamericana cresceu continuamente por quase uma década, o que causou alguns desajustes. O consumo privado e as dívidas de empresas e famílias aumentaram. O dólar foi apreciado, mas contribuiu para aumentar os déficits em conta corrente do país. Wall Street vivia mais uma febre especulativa. Era necessário, assim como o foi em 1928, que a Autoridade Monetária corrigisse tais desequilíbrios, principalmente no mercado acionário, de modo a evitar uma correção abrupta promovida pelo próprio mercado.

Em junho de 1999, a trajetória declinante dos juros que existia até então cedeu espaço a uma elevação das taxas. Posteriormente, percebeu-se que o que deveria ser uma soft landing passou a despertar preocupações de ocorrência de uma hard landing. Em janeiro de 2001, com a presença de sinais de desaquecimento e indicadores antecedentes que apontavam solavancos econômicos à vista, o Fed atuou reduzindo os juros, agindo de forma diferente daquela verificada no começo dos anos 1930 .

A reversão na tendência dos juros não impediu que efeitos adversos, resultantes da política contracionista adotada anteriormente, se manifestassem, sendo aprofundados pelos desdobramentos dos atentados terroristas de 11 de setembro de 2001. O produto desacelerou seu crescimento e chegou a registrar contração no terceiro trimestre de 2001, após 40 trimestres consecutivos de crescimento. As taxas de desemprego aumentaram, mas a economia não entrou em recessão. Os preços das ações sofreram correção baixista, mas as bolsas não colapsaram.

Discutir se o Fed errou ou não na medida e no timing da política monetária do final dos anos 1990 constitui aspecto relevante, mas não se deve desviar a atenção do objetivo aqui pro. posto. Alguns anos após a Depressão e em grande parte em virtude da não-aplicabilidade das teorias tradicionais ao mundo real da primeira metade dos anos 1930, Keynes, com sua Teoria Geral, deu grande impulso à visão macro da Economia. Desdo- 
bramentos e avanços posteriores permitiram o desenvolvimento da Macroeconomia e da Ciência Econômica como um todo, bem como dos bancos centrais (BCs).

O Federal Reserve de hoje é muito diferente daquele agrupamento de doze Reserve Banks que existiu no passado, nos aspectos institucionais, operacionais e teóricos. As transformações ocorridas no Sistema ao longo das últimas décadas fazem parte de um movimento mais amplo de evolução dos BCs e da política monetária. Movimentos em direção a mecanismos que visam incrementar credibilidade, independência e transparência permeiam o cotidiano dos bancos centrais da atualidade. Seus técnicos acompanham e analisam sistematicamente informações e dados que chegam sobre o estado da economia nacional e mundial. Avanços teóricos permitiram a elaboração de novos e melhores indicadores, tanto backward-looking quanto forwardlooking. No que tange à estrutura de decisões nos bancos centrais, prevalece hoje um modelo centralizado, inclusive na Zona do Euro.

Mas apesar dessa evolução, algumas dificuldades ainda estão presentes no âmbito da política monetária. Blinder (1999), com sua autoridade de acadêmico e ex-diretor de banco central, advoga que, na presença de incertezas acerca das previsóes, dos parâmetros e mesmo do modelo adotado, o melhor a fazer é não confiar em um único modelo e sim utilizar vários, assim como observar diversos indicadores. Ainda hoje não é possível praticar política monetária com absoluta certeza de como as coisas vão evoluir; não se deve estar com os olhos vendados aos desenvolvimentos teóricos e a indicadores considerados menos importantes, como ocorreu no passado, segundo a abordagem proposta por Brunner e Meltzer e Humphrey, pois não existem respostas universais em política monetária. Hoje há consciência de que refinamentos e desenvolvimentos posteriores na teoria e no instrumental utilizado podem revelar quão erradas estavam as decisões tomadas. Por isso, Blinder recomenda cautela e gradualismo, observação constante e ajustes pontuais. Contudo, uma política monetária estritamente passiva não teria espaço nas sociedades modernas. Cautela sim, mas com atuação ativa. 


\section{Conclusões}

A evolução ocorrida nas instituições políticas e econômicas, nos âmbitos nacional e supranacional, reduz em muito a probabilidade de ocorrência de uma outra Grande Depressão nos dias atuais na proporção em que aquela se deu. O Fed de hoje está mais maduro quando comparado ao Fed do final dos anos 1920. Evolução similar se verifica em outros BCs, em um contexto mais amplo de evolução da política monetária. Além disso, comportamentos totalmente passivos diante de eventuais crises econômicas não seriam aceitos com facilidade pelas sociedades modernas, mais cientes de seu poder de influência sobre as autoridades e instituiçōes públicas.

Diante de tal quadro, o ponto de vista aqui defendido é o de que será menos provável um comportamento passivo por parte dos BCs perante situações adversas. Mesmo bancos centrais de países que adotaram uma política monetária deliberadamente passiva, como foi o caso recente da Argentina, dispunham de uma margem de manobra, mesmo que estreita, para a tomada de decisões. ${ }^{16}$

Deve-se notar, contudo, que a política monetária constitui-se em assunto de grande complexidade; muitas vezes sua prática é mais arte do que ciência. O caso do Bank of Japan é sintomático, já que aquela instituição defronta-se com deflação e estagnação econômica há vários anos. Por isso, a ordem do dia deve ser, mais do que simplesmente permitir a liquidação dos excessos e desequilíbrios, manter uma postura ativa e um contínuo acompanhamento de indicadores micro e macroeconômicos, além dos desdobramentos financeiros e políticos. $\mathrm{O} \mathrm{BC}$ também não deve desconsiderar teorias alternativas e aspectos cuja natureza não seja estritamente econômica. Entre esses aspectos, ondas de otimismo que geram bolhas especulativas constituem um dos mais relevantes exemplos e estão presentes independentemente de quaisquer avanços que ocorram na política monetária e nos BCs.

\footnotetext{
16 No caso da Argentina, o currency board adotado em 1991 possuía uma cláusula de escape: uma fração da base monetária poderia ser respaldada por títulos públicos denominados em dólares. Essa cláusula foi acionada, por exemplo, no começo de 1995, quando os efeitos da Crise do México resultaram em perda de reservas internacionais.
} 


\section{Referências bibliográficas}

BERNANKE, Ben S. Nonmonetary effects of the financial crisis in the propagation of the Great Depression. American Economic Review, v. 73:3, p. 257-76, jun. 1983.

BLINDER, Alan S. Bancos Centrais. teoria e prática. São Paulo: Editora 34, 1999.

BRUNNER, Karl; MELTZER, Allan $\mathrm{H}$. What did we learn from the monetary experience of the United States in the Great Depression?. The Canadian Journal of Economics, v. 1:2, p. 334-48, maio 1968

EICHENGREEN, Barry. A globalização do capital. São Paulo: Editora 34, 2000.

EPSTEIN, Gerald; FERGUSON, Thomas. Monetary policy, loan liquidation, and industrial conflict: the Federal Reserve and the open market operations of 1932. The Journal of Economic History, v. 44:4, p. 957-83, dez. 1984.

FRIEDMAN, Milton; SCHWARTZ, Anna J. A monetary history of the United States, 1867-1960. Princeton: Princeton University Press, 1963, p. 240-419.

GALBRAITH, John K. 1929: O colapso da Bolsa. São Paulo: Pioneira, 1988.

HAMILTON, James D. Monetary Factors in the Great Depression. Joumal of Monetary Economics, v. 19, p. 145-69, 1987.

HUMPHREY, Thomas M. Monetary policy frameworks and indicators for the Federal Reserve in the 1920s. Federal Reserve Bank of Richmond Economic Quartely, v. 87, p. 6592, Winter 2001.

KUBIK, Paul J. Federal Reserve policy during the Great Depression: the impact of interwar attitudes regarding consumption and consumer credit. Journal of Economic Issues, v. XXX, n. 3, p. 829-42, set. 1996.

MISHKIN, Frederic S. Moeda, bancos e mercados financeiros. 5. ed. São Paulo: Editora LTC, 2000, p. 235-301.

POLLARD, Patrícia S. A look inside two central banks: the European Central Bank and the Federal Reserve. Review Federal Reserve Bank of St. Louis, v. 85, p. 11-30, jan./fev. 2003.

ROMER, Christina D. The Great Crash and the onset of the Great Depression. Quartely Journal of Economics, v. CV, n. 3, p. 597-624, ago. 1990.

ROMER, Christina D. What ended the Great Depression?. The Journal of Economic History, v. 52:4, p. 757-84, dez. 1992.

ROMER, Christina D. The Nation in Depression. Journal of Economic Perspectives, $\mathrm{v}$. 7:2, p. 19-39, Spring 1993.

TEMIN, Peter. Did monetary forces cause the Great Depression. Nova York: W.W. Norton G Company Inc. 1976.

WHEELOCK, David C. Conducting monetary policy without government debt: the Fed 's early years. Review Federal Reserve Bank of St. Louis, v. 84, p. 1-14, maio/jun. 2002.

WILNER, Adriana; COSTA, Luiz M. C. Assim tropeça a humanidade. Carta Capital, p. 1418, 14 ago. 2002. 